\title{
THE ABILITY OF CERTAIN ADRENOCORTICAL HORMONES TO POTENTIATE THE VASOCONSTRICTOR ACTION OF NOR-ADRENALINE ON THE CONJUNCTIVAL VESSELS IN THE RABBIT AND IN MAN*
}

\author{
BY \\ G. LEPRI AND R. CRISTIANI \\ From the Eye Clinic, University of Pisa, Italy (Director: Prof. M. Focosi)
}

From the observations of Ashton and Cook (1952) on the terminal vessels of the rabbit ear and those of Fritz and Levine (1951) and Zweifach, Shorr, and Black (1953) on the vessels of the mesoappendix of the adrenalectomized rat, it has been proved that the bloodvessels show an increased sensitivity to the local administration of nor-adrenaline when the animals have previously undergone general treatment with cortisone or ACTH. It has further been established that the adrenocortical steroids increase the muscular tone by implementing the pressor action of the nor-adrenaline. An increase in pressure after intravenous injection of nor-adrenaline has been demonstrated in the adrenalectomized dog (Ramey, Goldstein, and Levine, 1951) and also in man after the previous administration of high doses of cortisone (Kurland and Freedburg, 1951) or desoxycorticosterone acetate.

Reis (1960) has recently examined the responses of the vessels of the bulbar conjunctiva of normal subjects to nor-adrenaline after previous local application of adrenocortical hormones. He found that both cortisone and hydrocortisone potentiated the action of nor-adrenaline, and that deltacortisone produced an even more marked increase of sensitization.

The considerable importance of these results in the field of ophthalmology encouraged us to examine the problem further. The present research has been carried out on normal rabbits and subsequently on normal human subjects.

\section{Methods}

\section{(a) Animal Experiments}

(I) Eleven normal male rabbits weighing from 1.8 to $2 \mathrm{~kg}$. were used. The conjunctival vessels were observed by means of the Haag-Streit slit lamp, using a magnification of 47 diameters, which showed not only the arterioles and metaarterioles, but also the precapillary sphincters, capillaries, venules, and arteriovenous shunts.

In each animal, a limited area of the conjunctiva was examined and observations were made in that area alone, in order to eliminate local variations which might take place in different regions of the conjunctiva. The sensitivity of the precapillary sphincters and of the meta-arterioles was first tested by using serial dilutions of noradrenaline, buffered to $\mathrm{pH} \mathrm{7 \cdot 4}$ and introduced successively into the conjunctival sac, 
ranging from 1 in $1,000,000$ to 1 in 10,000 . $0 \cdot 2 \mathrm{ml}$. of each dilution was instilled into the conjunctival sac of each eye, starting with the highest. The highest dilution required to provoke a spasm of the precapillary and meta-arterial vessels, and to cause ischaemia of the field under observation, was noted. For any individual eye and area of conjunctiva, the same dilution was required on repeating the experiment, and in general both eyes of the same animal behaved in the same way. The vasoconstrictor action usually had the same duration, from 1 to 2 minutes, and similar results were obtained by both observers.

Having determined by this method the threshold of nor-adrenaline in each individual case, drops of adrenocortical hormone were instilled into the conjunctival sac of the right eye, the left being used as a control. Six rabbits were treated with hydrocortisone ( 2.5 per cent. suspension) and five with deltacortisone $(2.5$ per cent. solution), $0 \cdot 2 \mathrm{ml}$. being instilled on each occasion. After an interval of 15 minutes the graduated dilutions of nor-adrenaline, starting with the highest, were introduced into both eyes of each animal.

Results.-In the left (control) eyes the dilution required to cause vasoconstriction was the same as in the preliminary experiments. In all the eyes which had been previously treated with subconjunctival steroids a higher dilution of nor-adrenaline was required to produce vasoconstriction (Table I).

TABLE I

DILUTIONS (IN THOUSANDTHS) OF NOR-ADRENALINE REQUIRED TO PRODUCE VASO-CONSTRICTION IN RABBIT EYES TREATED WITH SUBCONJUNCTIVAL STEROIDS AND IN CONTROLS

\begin{tabular}{l|c|c|c}
\hline \multirow{2}{*}{ Steroid } & \multirow{2}{*}{ Rabbit No. } & \multicolumn{2}{|c}{ Eye } \\
\cline { 2 - 4 } & & Right (Steroid-treated) & Left (Control) \\
\hline & 1 & $1: 25$ & $1: 15$ \\
$0 \cdot 2$ ml. Hydrocortisone 2.5 per cent. & 2 & $1: 50$ & $1: 25$ \\
& 3 & $1: 50$ & $1: 35$ \\
& 5 & $1: 50$ & $1: 25$ \\
& 6 & $1: 100$ & $1: 10$ \\
\hline $0 \cdot 2$ ml. Deltacortisone 2.5 per cent. & 1 & $1: 25$ & $1: 25$ \\
& 2 & $1: 100$ & $1: 15$ \\
& 4 & $1: 50$ & $1: 25$ \\
& 5 & $1: 100$ & $1: 15$ \\
& & $1: 50$ & $1: 25$ \\
\hline
\end{tabular}

(II) In a second series of ten animals the threshold concentration of nor-adrenaline was determined 30 minutes after the intramuscular injection of $10 \mathrm{mg}$. hydrocortisone (5 rabbits) or $5 \mathrm{mg}$. deltacortisone (5 rabbits).

Results.-Table II (opposite) shows that there was no change in the concentration of nor-adrenaline necessary to provoke vasoconstriction after the intramuscular injection of the steroid, at least when observations were made 30 minutes later. 
TABLE II

DILUTIONS (IN THOUSANDTHS) OF NOR-ADRENALINE REQUIRED TO PRODUCE VASOCONSTRICTION IN EYES OF RABBITS BEFORE AND AFTER THE INTRAMUSCULAR INJECTION OF STEROIDS

\begin{tabular}{l|c|c|c}
\hline \multicolumn{1}{c|}{ Steroid } & Rabbit No. & Before Steroid Injection & After Steroid Injection \\
\hline \multirow{3}{*}{ Hydrocortisone 10 mg. } & 1 & $1: 10$ & $1: 10$ \\
& 2 & $1: 10$ & $1: 10$ \\
& 3 & $1: 35$ & $1: 25$ \\
& 4 & $1: 25$ & $1: 25$ \\
Deltacortisone 5 mg. & 5 & $1: 10$ & $1: 15$ \\
\hline & 1 & $1: 15$ & $1: 15$ \\
& 2 & $1: 10$ & $1: 25$ \\
& 3 & $1: 15$ & $1: 10$ \\
& 5 & $1: 10$ & $1: 10$ \\
\hline
\end{tabular}

\section{(b) Human Experiments}

Eleven healthy subjects, six men and five women aged from 15 to 39 years, were tested. As in the rabbit experiments, the threshold concentration of nor-adrenaline required was determined first. The experiment was then repeated in five subjects 15 minutes after the local instillation of $0.2 \mathrm{ml}$. of a suspension of 2.5 per cent. hydrocortisone into one eye, the other being used as a control, and a similar experiment was performed on six subjects, using a solution of 2.5 per cent. deltacortisone.

Results.-Table III shows that (in all but one case) the local application of steroids increased the sensitivity of the conjunctival vessels to nor-adrenaline.

The facts that the control eyes showed no increased sensitivity and that the parenteral administration of steroids had no effect on the sensitivity of the conjunctival vessels to nor-adrenaline in animals demonstrate that the effect is a local one.

TABLE III

DILUTIONS (IN THOUSANDTHS) OF NOR-ADRENALINE REQUIRED TO PRODUCE VASOCONSTRICTION IN HUMAN EYES TREATED WITH SUBCONJUNCTIVAL STEROIDS AND IN CONTROLS

\begin{tabular}{c|c|c|c}
\hline \multirow{2}{*}{ Steroid } & \multirow{2}{*}{ Subject No. } & \multicolumn{2}{|c}{ Eye } \\
\cline { 2 - 4 } & & Right (Steroid-treated) & Left (Control) \\
\hline & 1 & $1: 30$ & $1: 15$ \\
0.2 ml. Hydrocortisone 2.5 per cent. & 2 & $1: 20$ & $1: 10$ \\
& 3 & $1: 20$ & $1: 15$ \\
& 4 & $1: 20$ & $1: 15$ \\
\hline \multirow{3}{*}{0.2 ml. Deltacortisone 2.5 per cent. } & 1 & $1: 30$ & $1: 10$ \\
& 2 & $1: 25$ & $1: 15$ \\
& 4 & $1: 35$ & $1: 15$ \\
& 5 & $1: 30$ & $1: 20$ \\
& 6 & $1: 25$ & $1: 15$ \\
\hline
\end{tabular}




\section{Discussion}

The effects observed after the local administration of steroids can be attributed to the relatively high concentration at which they were used, and must therefore be considered not as a biological but as a pharmacological response. Our observations do not allow conclusions to be drawn in regard to other vessels, since the response of a specified vascular segment to the local application of vasomotor substances may differ from zone to zone (Zweifach and Metz, 1955). It is interesting to note that earlier clinical observations suggested that the vessels of the bulbar conjunctiva may be modified in certain endocrine disorders. Lee (1955) observed changes in the conjunctival vessels in cases of Cushing's syndrome, and other alterations in these vessels have been demonstrated in the course of the menstrual cycle (Landesman, Douglas, Dreispoon, and Holze, 1953) and in normal pregnancy (Landesman, Douglas, Dreispoon, and Lee (1953).

The results of the experiments here presented apply only to the conjunctiva, but they do indicate the possibility of a local action of corticosteroid hormones which may have some practical application.

\section{Summary}

The instillation into the conjunctival sac of the adrenocortical hormones hydrocortisone and deltacortisone increased the vasoconstrictor action of nor-adrenaline upon the conjunctival vessels. This was confirmed experimentally in the rabbit and in man, but the parenteral administration of the same hormones had no such effect.

\section{REFERENCES}

Ashton, N., and Cook, C. (1952). Brit. J. exp. Path., 33, 445.

Fritz, I., and Levine, R. (1951). Amer. J. Physiol., 165, 456.

Kurland, G. S., and FreedBerG, A. S. (1951). Proc. Soc. exp. Biol. (N. Y.), 78, 28.

Landesman, R., Douglas, R. G., Dreishroon, G., and Holze, E. (1953). Amer. J. Obstet. Gynec., 66, 988.

LeE, R. E. (1955). Amer. J. Med., 19, 203.

Ramey, E. R., Goldstein, M. S., and Levine, R. (1951). Amer. J. Physiol., 165, 450.

REIS, D. J. (1960). J. clin. Endocr., 20, 446.

ZWEIFACH, B. W., and MeTz, D. B. (1955). Amer. J. Physiol., 182, 155. SHORR, E., and BlACK, M. M. (1953). Ann. N.Y. Acad. Sci., 56, 626. 